\title{
ANÁLISE DE VÍDEOS EDUCACIONAIS NO YOUTUBE: CARACTERES E LEGIBILIDADE
}

\author{
Catiúcia Klug Schneider, MPET, IFSUL, catiucia.klug@gmail.com \\ Lélia Caetano, MPET, IFSUL, leliacaetano.ic@gmail.com \\ Luis Otoni Meireles Ribeiro, MPET, IFSUL, luis.otoni@gmail.com
}

\begin{abstract}
Resumo: Com a popularização dos vídeos educacionais no Youtube, os educadores encontram dificuldades na descoberta de parâmetros para a confecção adequada de vídeos. Diante disso, a pesquisa analisa os aspectos envolvidos na legibilidade dos textos e caracteres utilizados nos vídeos, em uma amostra intencional de vídeos da área de matemática postados no Youtube. Os resultados indicam que existem patamares mínimos para uma proporção adequada entre a altura da área útil de exposição do vídeo e a altura dos caracteres, abaixo da qual a legibilidade é comprometida, com pouca influência da resolução e do tamanho da tela de vídeo dos computadores móveis utilizados atualmente, que representam o caso mais crítico de uso, ao lado dos tablets e smartphones. Fatores como cor dos caracteres e do plano de fundo, contraste e reflexo também aparecem como relevantes na análise.
\end{abstract}

Palavras-chave: vídeos educacionais, Youtube, caracteres, legibilidade, objetos de aprendizagem

\section{ANALYSIS OF EDUCATIONAL VIDEOS ON YOUTUBE: CHARACTERS AND LEGIBILITY}

\begin{abstract}
With the popularization of educational videos on Youtube educators encounter difficulties in finding suitable parameters for making videos. The research examines the issues involved in the legibility of text and characters used in the videos in an intentional sample of videos of the area of mathematics posted on Youtube. The results indicate that there are minimum levels for a appropriate proportion between the height of the working area of exposure of the video and the height of the characters, below which the legibility is compromised, with little influence of the resolution and size of the video screen of the mobile computers used currently representing the most critical case of use, along with the tablets and smartphones. Factors such as color of characters and background, contrast and reflection also appear as relevant in the analysis.
\end{abstract}

Keywords: educational videos, Youtube, characteres, legibility, learning objects

\section{Introdução (Internet \& Youtube)}

A internet caracteriza-se pela multiplicidade de materiais e informações disponíveis. Além disso, o ritmo exponencial do seu crescimento não dá mostras de que irá se arrefecer. Dentre os diversos fenômenos de popularidade que surgem na internet, em períodos cada vez mais curtos, estão as "celebridades" oportunizadas pelo sucesso do Youtube. 
Classificada pela Google como uma plataforma de distribuição de conteúdos (Youtube, 2012), ela oportuniza, a um número incontável de usuários, descobrir, ver e compartilhar vídeos, caseiros ou profissionais, criados com originalidade ou modificados numa abordagem alternativa. No ciclo vida da internet, tal plataforma não pode ser classificada como recente, por ter sido fundada em fevereiro de 2005, nem tão pouco demonstra evidências de ter atingido seu apogeu para iniciar uma fase de declínio.

Já ao que se relaciona ao foco da pesquisa, não interessam os hits, os videoclipes musicais, seriados, trailers de filmes e jogos digitais, mas sim a velha área dos vídeos educacionais (Ferrés, 1996). Hoje, revigorados, os vídeos e animações postadas no Youtube, com ou sem a intenção de uso educacional, acabam por ser utilizados com caráter educativo ou, no mínimo, informativo.

Numa plataforma que tem como tônica o compartilhamento de vídeos, os protagonistas descobriram que sempre existirá um público internauta interessado em assistir àquele vídeo caseiro, o qual demonstra como instalar ou trocar um disco rígido (HD) em um notebook, ou como preparar aquela receita de biscoitos caseiros da vovó e, até mesmo, como calcular a hipotenusa de um triângulo retângulo utilizando o Teorema de Pitágoras!

Esse último aspecto poderia passar despercebido, não fosse a audiência expressiva dos vídeos educacionais e a divulgação na imprensa desse movimento crescente. A reportagem veiculada na Revista VEJA, edição 2.254 de fevereiro de 2012, traz em sua capa o matemático Salman Khan, responsável pela iniciativa Khan Academy, que atinge 4 milhões de alunos com seus vídeos na internet. De acordo com a reportagem, esses alunos já assistiram a 115 milhões de lições, num repositório, a época, com 2700 vídeos e exercícios gratuitos em 40 áreas do conhecimento (Veja, 2012). Atualmente, este número já atingiu mais de 3200 vídeos, já traduzidos para diversos idiomas, inclusive o português.

Nesse sentido, alguns aspectos chamam a atenção para esse fenômeno de audiência no Youtube. O primeiro refere-se ao equipamento utilizado para a confecção dos vídeos - uma câmera digital, um tablet conectado a um PC e uma caneta digital com a qual Khan desenha os gráficos, caracteres e símbolos os quais ilustram seus vídeos caseiros. O segundo é que a audiência veio de um público de jovens e crianças, que, por iniciativa própria, acessavam os vídeos para esclarecerem suas dúvidas de aprendizado. Vale a pena destacar que o uso dos vídeos do Khan em salas de aula, em ambientes escolares, é fato mais recente e, segundo o autor, não se configura como meta principal da Khan Academy.

Longe de ser um caso isolado, a proliferação de vídeos educacionais no Youtube cresce exponencialmente, como em diversas outras instâncias na internet. Para se ter uma ideia do número de vídeos relativos à matemática, foram encontrados cerca de 71.300 vídeos em português com a palavra "matemática" no título, e cerca de 16.600 vídeos em português com a palavra "cálculo" no título (busca em Maio/2012), mesmo sendo um assunto considerado difícil para a maioria dos internautas. Também, é possível inferir que existam outros vídeos disponíveis relacionados a essas temáticas no Youtube, mas que não tenham recebido essas expressões em seus descritores, já que é o próprio usuário que insere o texto relacionado ao vídeo compartilhado.

$\mathrm{O}$ assunto assume uma maior importância pela necessidade dos educadores de apropriarem-se dos saberes próprios e da linguagem referente a essa mídia em especial 
(Silva, 2010). É preciso investigar como o vídeo se reconfigura ao ser veiculado na internet e quais premissas, já consolidadas em anos de pesquisa e prática na televisão e no cinema, podem ser transpostas para esse novo canal de exibição - a internet e, em particular, o Youtube com suas limitações e vantagens. Somando-se a isso, a própria área dos vídeos educacionais tem demandas específicas, que não podem ser desconsideradas na ambiência gerada pela Youtube.

Contudo, o escopo do artigo abrangerá a análise dos textos, ou melhor, da apresentação dos caracteres nos vídeos educacionais. Ao analisar uma série de vídeos relacionados à área de matemática, é fácil notar a utilização maciça de caracteres alfanuméricos para a demonstração de cálculos, identificação de variáveis e gráficos. No entanto, foram encontradas evidências de que não existe uma preocupação ou métrica respeitada que garanta a legibilidade desses textos, os quais são visíveis nos vídeos educacionais, tanto nos vídeos considerados caseiros quanto naqueles que denotam uma abordagem mais profissional.

A pesquisa revela que parâmetros devem ser respeitados para que os textos exibidos nos vídeos educacionais do Youtube possam ter sua legibilidade garantida. Tais informações são relevantes diante do cenário atual, em que ocorre uma proliferação dos dispositivos móveis que permitem acesso à internet. A convergência de tecnologias e dispositivos para internet aponta na direção de um uso intensivo de vídeos a serem visualizados em plataformas e dispositivos diversos, abrangendo toda a gama de notebooks, netbooks, smartphones, tablets e celulares de última geração.

Mobilidade e conectividade são vetores de desenvolvimento que não demonstram sinais de enfraquecimento na sociedade atual, sendo assim a problemática de legibilidade dos caracteres textuais expostos nos vídeos, com possibilidade de uso pedagógico ou não, merecerá cada vez mais destaque, e os pesquisadores da área educacional e tecnológica terão campo fértil de pesquisa.

\section{Vídeos \& Textos - uma nova relação no Youtube}

A linguagem do vídeo tem uma natureza sintética, articula imagens, sons, falas e poucos textos, criando uma superposição de códigos e significações, predominantemente audiovisuais (Moran, 2012).

$\mathrm{O}$ vídeo tem um poder de ilustração muito forte, prende atenção quando bem estruturado e elaborado. Tem movimento, áudio e, muitas vezes, é autoexplicativo. A tecnologia está cada vez mais presente na vida dos alunos e em virtude desse dinamismo, a produção de vídeos digitais de curta duração está cada vez mais popular. Entre as páginas com maior número de acessos na internet, estão aquelas que permitem assistir aos vídeos e disponibilizá-los (Moore, 2010).

Há muitas formas de denominar um vídeo, pressupondo características e formatos distintos em relação ao seu conteúdo e/ou tratamento tecnoestético, assim um vídeo pode ser educacional ou documentário, profissional ou caseiro. Seja qual for a estratégia utilizada, o vídeo é uma mídia que pode auxiliar no processo de ensino e aprendizagem, pois trabalha com uma infinidade de informações que podem ser exploradas de diversas maneiras.

A produção de materiais educacionais, incluindo os vídeos, atenta para princípios formais básicos quanto à clareza, distribuição harmônica dos elementos visuais e aspectos relacionados à legibilidade da escrita. Quando um conteúdo 
educacional é apresentado em um vídeo, estes mesmos princípios permanecem e, ainda incluem outros específicos da própria mídia e sua veiculação.

Além disso, as características como cor, fonte, tamanho, relação com o plano de fundo e a posição e interação que cada elemento desempenha representam um papel importante no aprendizado e têm suas especificidades de utilização. Cada detalhe deve ser devidamente escolhido e planejado para que a composição visual final seja atrativa, legível e adequada ao público.

Diante disso, é importante que os materiais sejam desenvolvidos de forma a satisfazer as necessidades de adequada estrutura formal, e para esse objetivo ser atingido, é preciso que se tenha conhecimento e embasamento dos estudos e experiências realizados pela Gestalt ${ }^{1}$ no campo da percepção visual (Filho, 2009).

Em sua grande maioria, os vídeos com conteúdo educacional disponibilizados no Youtube priorizam a combinação da linguagem verbal e textual, apresentando-se num formato de aula expositiva, onde o professor explica o conteúdo e, prioritariamente, usa textos como principal recurso para auxiliar na organização da apresentação, ampliar a percepção e enfatizar determinados tópicos do tema.

Normalmente, os textos encontrados nos vídeos são títulos, legendas, massa de textos e textos de apoio, incluindo caracteres alfanuméricos para a demonstração de cálculos, identificação de variáveis e gráficos. A tipografia utilizada na composição dos vídeos varia entre a digital e a manuscrita realizada em folhas de papel, lousa digital e interfaces de programas gráficos.

A tipografia faz com que o conteúdo ganhe forma, a linguagem um corpo físico e as mensagens um fluxo social (Lupton, 2008). Ela pode ser digital, referindo-se às famílias de tipos que são utilizados nos computadores pessoais em diversas aplicações e que podem ser colocados em escala, segundo o tamanho desejado, ou então manuscritas, referindo-se à forma quotidiana de escrita manual, muito utilizada nos vídeos considerados caseiros.

O problema central consiste em como assegurar uma boa legibilidade nos textos presentes nos vídeos educacionais. Que fatores interferentes garantem que a tipografia digital ou manuscrita presente nos vídeos atenda às necessidades dos usuários? Será suficiente garantir um bom contraste, simplicidade e proporção, baseando-se nos fundamentos gerais do design, e não específicos para a criação de vídeos, para que o objetivo de legibilidade seja alcançado?

\section{Vídeos educacionais no Youtube - a legibilidade em análise}

A escolha para análise dos vídeos educacionais foi feita levando em consideração três características diferentes: aqueles produzidos de forma caseira, utilizando na maioria das vezes a sala de aula como cenário e o quadro branco ou folha de papel como apoio; vídeos disponibilizados em canais ${ }^{2}$ do Youtube, que incorporam recursos diferenciados na produção, na maioria das vezes, com apoio de tablets e softwares de captura de tela, áudio, etc.; como também vídeos de instituições profissionais, normalmente produzidos para a TV e convertidos para serem postados no Youtube, pelas próprias empresas ou parceiros comerciais. A intenção foi reunir um material de pesquisa rico de informações, o qual contemplasse diferentes linguagens e estilos referentes a essa mídia.

Para garantir uma menor variabilidade na visualização dos vídeos do Youtube, foram tomados alguns cuidados. A escolha do navegador de internet (browser) e a 
resolução do monitor utilizada como base para a relação de proporções presentes nesse estudo foram feitas a partir de constatações que levaram em consideração o tamanho da área visível do $\operatorname{site}^{3}$ e o padrão utilizado pela maioria dos usuários. Para análise, foram utilizadas apenas as medidas de altura dos elementos interferentes. Conforme a Figura 1, constatou-se que a largura da área do vídeo não influência na legibilidade dos textos, apenas na quantidade de caracteres apresentados, o que para esse estudo não se mostrou relevante.

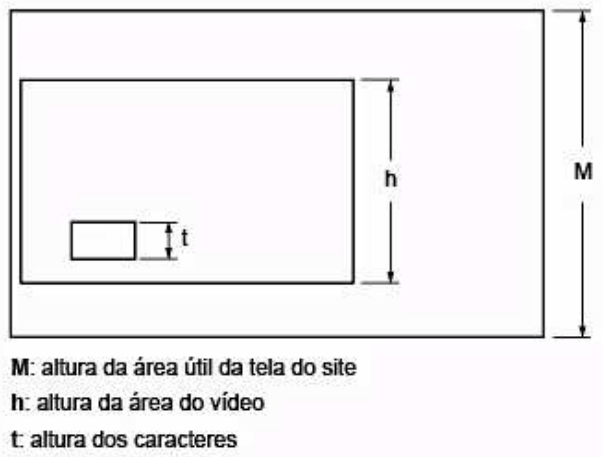

Figura 1 - Elementos e proporções na página do Youtube

Num primeiro momento, os browsers Firefox, Chrome, Internet Explorer e Safari foram testados em relação ao tamanho da área do site visível em cada um deles. Os browsers trazem como padrão a visualização do menu, abas de navegação e barra de navegação. A exceção é o navegador Chrome que apresenta apenas abas e barra de navegação. A diferença na área útil visível da página web não se mostrou significativa diante dos objetivos desse estudo, focalizado nos aspectos da legibilidade dos caracteres textuais que aparecem nos vídeos.

Os dados da pesquisa demonstraram que as características relacionadas com a legibilidade estão correlacionadas com o tamanho proporcional do texto comparado com a altura da tela do vídeo. Sendo assim, as proporções dos caracteres são trazidas em relação ao tamanho da área gráfica usada para a exposição do vídeo e não em relação à área visível do site. A Figura 2 apresenta um exemplo comparativo entre dois vídeos do Youtube, a tela 1 mostra um texto de baixa legibilidade e a tela 2 um texto legível. Vários fatores interferem no aspecto da legibilidade e serão analisados na pesquisa.
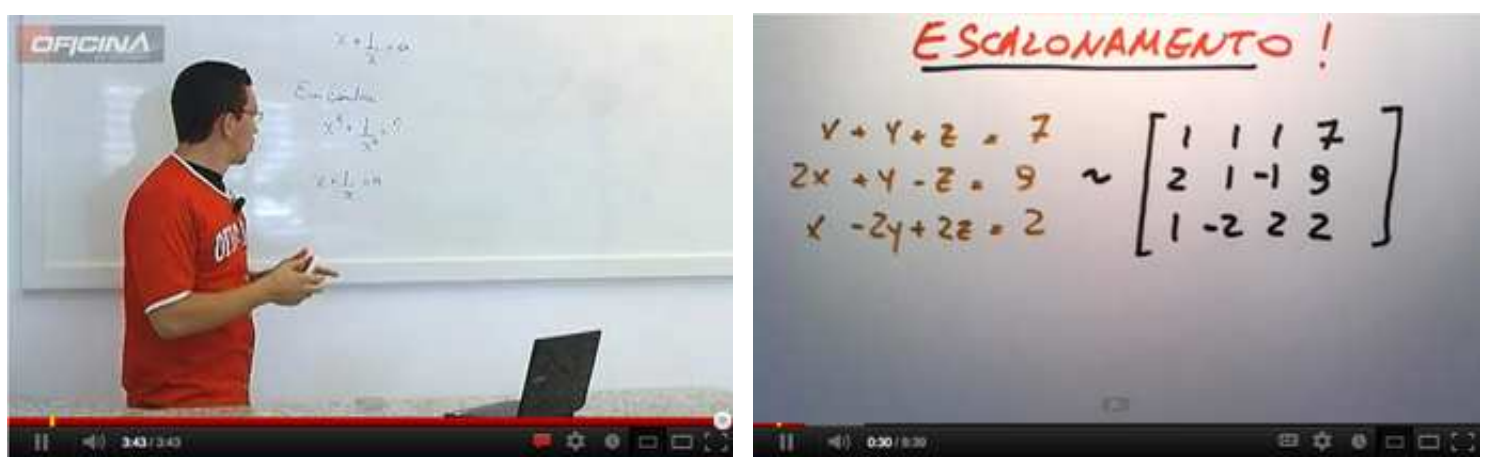

Figura 2 - Comparativo: Tela 1 (legibilidade ruim) x Tela 2 (legibilidade boa)

Um fator interferente na visibilidade da página web é a resolução da tela do monitor. Essa pode ser configurada pelo usuário, levando em conta a capacidade de processamento da placa gráfica de vídeo e do tipo de monitor que compõem o conjunto 
do dispositivo de acesso à internet. Entre as resoluções da tela do monitor, as mais usadas atualmente são 1024x768, 1280x800 e 1366x768. Nelas, foi possível analisar que não existe diferença significativa no tamanho da área gráfica utilizada pelo vídeo apresentado no site Youtube. Resoluções menores perdem área visível do site, apenas no sentido da largura, o que influencia na navegação do site, mas não na visualização do vídeo.

Também foi analisada a resolução 800x600 que apresentou a área do vídeo ocupando grande parte da área visível do site, o que gera uma perda considerável na visualização de áreas laterais do site. Esse aspecto compromete a navegação adequada, pois leva o usuário a utilizar uma barra de rolagem horizontal para poder ver toda a tela.

Diante dessas informações, a resolução $1024 \times 768$ foi escolhida para montagem da proporção do tamanho do vídeo e da área visível do site, pois é a resolução mais utilizada atualmente, além de apresentar-se como configuração padrão utilizada pela maioria das fábricas de computadores e ser a configuração mínima dos computadores portáteis menores, como os netbooks. A coleta das imagens foi feita utilizando o browser Internet Explorer, em virtude de ser um navegador da web padrão, previamente instalado, na maioria dos computadores com sistema operacional Windows.

Os vídeos educacionais ou informativos podem trazer os dados a partir de uma escrita manual, presente em muitos vídeos caseiros, ou ainda uma tipografia digital, onde o vídeo já apresenta características de uma produção auxiliada por equipamentos de captura de digitação, por exemplo.

As escolhas em relação aos aspectos visuais dessas tipografias, como o tamanho, a cor, a posição, a relação com o plano de fundo é, muitas vezes, feita de forma intuitiva, empírica. Os caracteres, na maioria dos vídeos analisados, apresentam-se sem um planejamento e cuidado em relação a esses aspectos, o que acarreta a ilegibilidade dos textos.

Os vídeos analisados, por serem da área da matemática, apresentam caracteres alfanuméricos que auxiliam na explicação do conteúdo que está sendo explorado. Esses caracteres são utilizados na forma de legendas, títulos, fórmulas, gráficos, textos de apoio.

A opção por seis vídeos de uma mesma área de conhecimento teve em vista manter certa similaridade dos conteúdos, fator que poderia ser relevante para a análise dos textos. A Tabela 1 apresenta um quadro com os dados coletados a partir dos vídeos selecionados no site Youtube. Os vídeos foram escolhidos levando em consideração as características diferenciadas de vídeos caseiros, de canais e profissionais, logo, a partir da identificação dos grupos foi feita uma escolha aleatória entre os vídeos.

Tabela 1 - Quadro comparativo dos elementos relacionados ao vídeo ${ }^{4}$ 


\begin{tabular}{|c|c|c|c|c|c|c|c|}
\hline & MANUSCRITO & REFLEXO & COR & FUNDO & CONTRASTE & PROPORÇÃO & LEGIBILIDADE \\
\hline LEGENDA & - & - & - & - & - & - & - \\
\hline TÍTULO & sim & กล̃o & várias & branco & bom & $h / 10$ & $\mathrm{O}$ \\
\hline TEXTO & sim & กล̃o & várias & branco & bom & $h / 18$ & 0 \\
\hline TEXTO DEAPOIO & - & - & - & - & - & - & - \\
\hline LEGENDA & - & - & - & - & - & - & - \\
\hline TÍTULO & - & - & - & - & - & - & - \\
\hline TEXTO & sim & sim & preto & branco & ruim & $\mathrm{h} / 56$ & 0 \\
\hline TEXTO DEAPOIO & - & - & - & - & - & - & - \\
\hline LEGENDA & - & - & - & - & - & - & - \\
\hline TÍTULO & กล̃o & กล̃o & preto & figura & médio & $\mathrm{h} / 14$ & 0 \\
\hline TEXTO & กล̃o & กão & preto & figura & ruim & $h / 39$ & $\theta$ \\
\hline TEXTO DEAPOIO & - & - & - & - & - & - & - \\
\hline LEGENDA & não & กão & branco & preto & bom & $h / 35$ & $\mathrm{O}$ \\
\hline TÍTULO & กล̃o & กão & várias & figura & bom & $\mathrm{h} / 12$ & 0 \\
\hline TEXTO & não & กล̃o & várias & colorido & bom & $h / 16$ & 0 \\
\hline TEXTO DEAPOIO & กล̃o & não & branco & figura & bom & $\mathrm{h} / 9$ & 0 \\
\hline LEGENDA & - & - & - & - & - & - & - \\
\hline TÍTULO & กão & กลีo & branco & verde & bom & $\mathrm{h} / 26$ & 0 \\
\hline TEXTO & não & กล̃o & várias & verde & médio & h/56 & 0 \\
\hline TEXTO DEAPOIO & - & - & - & - & - & - & - \\
\hline LEGENDA & - & - & - & - & - & - & - \\
\hline TÍTULO & sim & กล̃o & várias & preto & bom & $\mathrm{h} / 56$ & $\theta$ \\
\hline TEXTO & sim & กล̃o & várias & preto & bom & $h / 65$ & 0 \\
\hline TEXTO DEAPOIO & - & - & - & - & - & - & - \\
\hline
\end{tabular}

A categorização da legibilidade textual que foi definida para a análise levou em consideração alguns aspectos formais como a cor dos caracteres e se eram manuscritos, a cor do plano de fundo, a incidência de reflexo e a relação desses elementos. A partir dos dados, foi possível analisar o contraste e, por fim, a legibilidade dos textos, títulos, legendas e textos de apoio.

Na primeira coluna do quadro, foi analisado se o texto utilizado é manuscrito. Os vídeos com textos escritos a mão apresentam um ritmo mais natural em relação à fala, existe uma sincronicidade da ordem da memória relacionada a uma aula presencial. Os caracteres alfanuméricos, sinais gráficos e o movimento de setas de indicação, por exemplo, aguçam a percepção visual e prendem a atenção. Algumas vezes, em decorrência do desenvolvimento da proposição apresentada, alguns caracteres manuscritos aparecem numa proporção menor, comprometendo o contraste e a proporção pequena em relação ao tamanho da área gráfica usada para exposição do vídeo. Neste tópico, as análises realizadas nas categorias estabelecidas revelam que esta forma de apresentação manuscrita tende a comprometer a legibilidade do texto de forma esporádica.

Já na segunda coluna, o elemento de análise foi o reflexo de luz projetado no plano de fundo utilizado como suporte para os textos apresentados no vídeo. Houve a incidência de reflexo em relação à superfície de um quadro branco e este tipo de ocorrência compromete a leitura do texto, não por causa do contraste e proporção, mas pela refração da luz. O reflexo da luz comprometeu a legibilidade dos caracteres textuais durante toda a exibição do vídeo em função do posicionamento estático da câmera.

A terceira e a quarta coluna do quadro trazem informações sobre os caracteres e o plano de fundo. Nos textos, títulos, legendas e textos de apoio foram observados que V. $10 \mathrm{~N}^{\mathrm{o}} 1$, julho, 2012 
alguns aspectos chamam a atenção, e para que as informações presentes neles sejam legíveis, um dos aspectos principais encontra-se nas cores escolhidas para estes textos, como o consequente contraste com o plano de fundo. Quando observamos o uso de cores na apresentação de caracteres, percebemos a intenção de reforçar visualmente a informação desejada, a visibilidade e a acuidade visual são estimuladas para o contexto previsto (Lupton, 2008).

Nos vídeos analisados, foi possível observar que a grande maioria apresenta caracteres e plano de fundo nas cores preto e branco, seguindo a lógica do contraste. Alguns vídeos que possuem textos coloridos apresentaram problemas de legibilidade, mas não em virtude das cores, mas sim porque os caracteres não estão dentro de uma proporção de altura mínima necessária para a legibilidade.

Já em relação ao plano de fundo utilizado na montagem dos vídeos, um dos elementos responsáveis pelo contraste foi a cor do plano de fundo, a qual interfere diretamente no contraste dos textos, podendo comprometer ou beneficiar a legibilidade. Segundo Lupton, a percepção visual do ser humano é definida nas relações figura/fundo - uma forma (figura) será sempre vista em relação ao que existe em seu entorno (fundo). Isto ocorre quando estamos assistindo a um vídeo com legendas. Normalmente, teremos dificuldades para ler legendas com caracteres na cor preta, quando a cena apresenta-se num ambiente escuro (2008).

O contraste foi o elemento analisado na quinta coluna do quadro. O contraste é uma ferramenta de expressão que intensifica significados e simplifica a comunicação, ao mesmo tempo em que estimula e atrai a atenção. Em todos os sentidos, a estimulação visual quando relacionada à manutenção da atenção e intensificação do significado, interfere decisivamente no fator da proporção e da escala, que pensadas como forças e informações visuais, associam-se para realçar o contraste (Lupton, 2008).

$\mathrm{Na}$ análise do contraste, foi possível observar a legibilidade dos caracteres, considerando-o em relação às cores utilizadas no plano de fundo e textos, como também a relação de contraste por proporção entre a altura dos caracteres e a altura da área gráfica do vídeo. O que se pode perceber é que a legibilidade dos caracteres depende tanto da relação de contraste entre cores como do contraste por proporção de tamanho dos elementos.

$\mathrm{Na}$ sexta coluna, foi analisada a proporção dos caracteres textuais em relação à altura da área gráfica usada para exposição do vídeo. A proporção é a característica decisiva para a legibilidade dos caracteres, quando relacionada com os demais elementos visuais que compõem o contexto. Durante a análise dos vídeos, foi possível perceber que em alguns casos a proporção dos caracteres estava dentro do limite adequado à legibilidade, mas os elementos não apresentavam contraste suficiente, deixando o texto ilegível. Já em outros vídeos, os caracteres e o fundo apresentavam contraste, mas a proporção era pequena, sendo assim, o texto também ficou ilegível.

Ainda considerando o contexto dos vídeos, pode-se afirmar que a proporção é crítica como fator de legibilidade, mas os princípios baseados na Gestalt são imperativos nas considerações analíticas deste contexto, onde a proporção dos caracteres textuais deve adequar-se como um fator de equilíbrio e harmonia. Ou seja, a legibilidade dos caracteres está ligada tanto ao contraste de cores quanto à proporção dos elementos.

Por fim, a sétima coluna do quadro classifica os elementos textuais do vídeo como bom, médio e ruim de acordo com a legibilidade apresentada, levando em 
consideração os dados anteriores. É importante destacar que a legibilidade dos caracteres depende de algumas características específicas da letra e também de alguns outros fatores como a luminosidade, o contraste entre letra e fundo e a fadiga visual do leitor (Niemeyer, 2006).

A partir das análises presentes na pesquisa, foi possível verificar que o contraste dos caracteres com o plano de fundo é um fator determinante na legibilidade dos textos, juntamente com a proporção dos caracteres em relação à área gráfica de exibição do vídeo, uma vez que quando se trata de considerar o conjunto da composição visual, segundo Lupton "os elementos devem ser combinados com um sentido de ordem e unificação, de maneira que cada um deles seja parte integrante e do todo. A proporção implica, obviamente, sempre uma comparação entre dois ou mais elementos." (2008, p.71)

\section{Youtube e perspectivas para os vídeos educacionais}

É importante destacar a crescente procura dos vídeos no Youtube, por parte de estudantes, os quais encontram neste serviço um repositório variado de possibilidades para atender suas necessidades de aprendizagem. Os vídeos mais assistidos refletem uma aprovação quanto à sua eficácia, além de sinalizarem uma avaliação para os futuros usuários. Estes vídeos podem ser aliados no processo de ensino e aprendizagem, principalmente se forem desenvolvidos utilizando-se de toda a potencialidade da linguagem audiovisual da mídia vídeo.

Outro aspecto importante a ser considerado é o perfil cognitivo do usuário dos vídeos educacionais que, a priori, são mobilizados de forma independente, na busca de aprendizagem, que ocorre de forma autônoma (Matta, 2006). Ao mesmo tempo, já existem muitos educadores que lançam mão deste tipo de vídeo para dar apoio as suas aulas presenciais ou a distância, quando não utilizam o próprio vídeo como um meio para produzir conhecimento, através da construção de vídeos experimentais com alunos e seu posterior compartilhamento.

Para a construção de um vídeo educacional, deve ser levado em consideração que o usuário procura por uma informação clara, objetiva e agradável, por isso os elementos compositivos do vídeo devem ser pensados no sentido de auxiliar nesse processo. A relação entre som, imagem e texto deve ser interconectada e relacionada através dos títulos, legendas e massa de textos, especialmente quando os textos são priorizados na apresentação.

Os conhecimentos, mesmo que básicos, de alguns parâmetros de design, principalmente relacionados à legibilidade dos textos e embasados nos estudos e experiências realizados pela Gestalt, são importantes para que se possa mudar, ousar e inventar novas maneiras de ver e construir vídeos. É fundamental assinalar que as escolhas dos elementos visuais que serão enfatizados assim como a manipulação desses elementos resultarão na qualidade dos vídeos educacionais

O Youtube é um grande aliado do educador e do estudante enquanto usuários. Contudo, quando assumimos uma postura ativa de produção do conhecimento, a condição de produtor é adotada. Nesse novo desafio, é importante ter-se sempre em mente que vídeos educacionais para compartilhamento são poderosas ferramentas de aprendizagem e divulgação de conhecimento (Ferrés, 1996), por isso é estratégico o uso de bom senso nas escolhas e formatos dos vídeos. 
Dessa forma, o importante é estabelecer novas maneiras de pensar e planejar os conteúdos e sua forma de transmissão quando estamos produzindo recursos de aprendizagem que serão compartilhados na web. Além das preocupações relativas ao processo pedagógico em si e o seu roteiro didático, precisamos articular competências específicas do meio digital e das linguagens que estamos utilizando como meio para transmitir estes conteúdos.

O cenário futuro abre possibilidades ainda mais intensivas de vídeos educacionais na internet. O próprio site do Youtube lançou, em dezembro de 2011, o Youtube para Escolas (http://www.youtube.com/education), com a pretensão de oferecer às escolas "acesso a centenas de milhares de vídeos educacionais gratuitos no YouTube EDU. Esses vídeos são provenientes de organizações reconhecidas, como Stanford, PBS e TED, bem como de parceiros influentes do YouTube com milhões de visualizações, como Khan Academy, Steve Spangler Science e Numberphile." (Wwwhatsnew, 2011)

Portanto, com a proliferação dos dispositivos móveis com acesso à internet e o uso crescente do Youtube como repositório acessível de vídeos educacionais (Mattar, 2009), a descoberta de parâmetros para o uso de textos em vídeos no Youtube assumirá maior importância para professores e pesquisadores educacionais interessados em produzir objetos de aprendizagem. Com certeza, tablets e smartphones irão demandar esforços mais consistentes na pesquisa de métodos e padrões para desenvolvimento de artefatos educacionais digitais.

\footnotetext{
${ }^{1}$ Gestalt é uma escola de psicologia experimental. O movimento gestaltista atuou principalmente no campo da teoria da forma, com contribuição relevante aos estudos da percepção, linguagem, inteligência, aprendizagem, memória, motivação, conduta exploratória e dinâmica de grupos sociais. (Filho, 2009, p.18)

${ }^{2}$ Ao criar uma conta no Youtube o usuário torna-se um membro registrado e o site oferece um canal pessoal. O canal permite que o usuário organize os vídeos carregados, além de usufruir várias funcionalidades interativas com os demais membros, a exemplo das redes sociais.

${ }^{3}$ Área visível do site: com a página do site maximizada, considera-se o espaço visível útil que fica abaixo das barras de menu e de ferramentas e aba de navegação, mas acima da barra de tarefas inferior (Windows) ou dock (Mac OS).

${ }^{4}$ Vídeo 1 - http://www.youtube.com/watch?v=TIs7FQKpXEw\&feature=related

Vídeo 2 - http://www.youtube.com/watch?v=hY9dJEMHupg\&feature=relmfu

Vídeo 3 - http://www.youtube.com/watch?v=DPBDcYyA7DY

Vídeo 4 - http://www.youtube.com/watch?v=CBmkBNwTLcU\&list=PL431BBE28FE960C31\&index=4

\&feature=plpp_video

Vídeo 5 - http://www.youtube.com/watch?v=HyT-54ScyFM\&feature=fvsr

Vídeo 6 - http://www.youtube.com/watch?v=Jsiy4TxgIME\&list=PLD6DA74C1DBF770E7\&index=1\&

feature=plpp_video fvsr
}

\section{Referências Bibliográficas}

FERRES, Joan. Vídeo e educação. 2ed. Porto Alegre: Artes Médicas, 1996.

FILHO, João G. Gestalt do Objeto: sistema de leitura visual da forma. 8ed. São Paulo: Escrituras Editora, 2009.

LUPTON, Ellen; PHILLIPS, Jennifer C. Novos Fundamentos do Design. São Paulo: Cosac Naify, 2008. 
MATTA, Alfredo Eurico Rodrigues. Tecnologias de aprendizagem em rede e ensino de história - utilizando comunidades de aprendizagem e hipercomposição. Brasília: Líber Livro Editora, 2006.

MATTAR, João. Youtube na educação: o uso de vídeos em EAD. Disponível em: <http://www.abed.org.br/congresso2009/CD/trabalhos/2462009190733.pdf>. Acesso em 11 maio 2012.

MOORE, Michael G. Educação a distância: uma visão integrada/ Michael Moore, Greg Kersley; [tradução Roberto Galman]. São Paulo, SP: Cengage Learning, 2010.

MORAN, José Manuel. O Vídeo na Sala de Aula. Disponível em: <http://www.eca.usp.br/prof/moran/vidsal.htm\#comover>. Acesso em 11 maio 2012.

NIEMEYER, Lucy. Tipografia: Uma apresentação. Rio de Janeiro: 2AB, 2006.

SILVA, Marco. Sala de aula interativa: educação, comunicação, mídia clássica... 5ed. São Paulo: Edições Loyola, 2010.

VEJA. Revista. O mundo de um novo ângulo. Reportagem de Weinberg, Mônica. Edição 2.254, ano 45, no 5, de 01/02/2012, p. 64-71. Editora Abril, 2012.

WWWHATSNEW. Google apresenta Youtube para Escolas, apenas vídeos educacionais. Disponível em: <http://br.wwwhatsnew.com/2011/12/google-apresentayoutube-para-escolas-apenas-videos-educacionais/>. Acesso em: 10 maio 2012.

YOUTUBE. Sobre 0 Youtube. Disponível em: <http://www.youtube.com/t/about_youtube>. Acesso em: 10 maio 2012. 